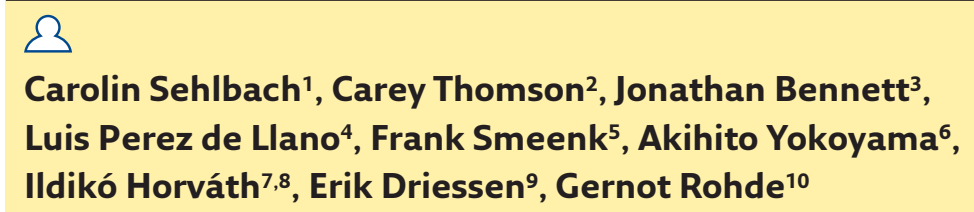

[1]

'Maastricht University, Faculty of Health, Medicine and Life Sciences, Educational Development and Research, Maastricht, The Netherlands. ${ }^{2}$ Pulmonary and Critical Care Division, Mount Auburn Hospital, Harvard Medical School, Boston, MA, USA. ${ }^{3}$ Respiratory Medicine, University Hospitals of Leicester NHS Trust, Leicester, UK. ${ }^{4}$ Pulmonology Dept, Hospital Universitario Lucus Agusti, Lugo, Spain. ${ }^{5}$ Catharina Hospital, Respiratory Medicine, Eindhoven, The Netherlands. ${ }^{6}$ Dept of Hematology and Respiratory Medicine, Kochi Medical School, Kochi University, Nankoku, Kochi, Japan. ${ }^{7}$ National Koranyi Institute for Pulmonology, Budapest, Hungary. ${ }^{8}$ Dept of Pulmonology, Semmelweis University, Budapest, Hungary. ${ }^{9}$ Maastricht University, Faculty of Health, Medicine and Life Sciences, Educational Development and Research, Maastricht, The Netherlands. ${ }^{10}$ Maastricht University Medical Centre, Respiratory Medicine, Maastricht, The Netherlands.

\title{
Re-certification of respiratory professionals: current practice and the future - educational forum report
}

To create an overview on re-certification procedures across the globe, the European Respiratory Society (ERS) organised an educational forum on "Re-certification: current practice and the future" during the 2016 International Congress in London, UK. During this educational forum, the importance of re-certification and international procedures were discussed. Panellists from Japan, the Netherlands, Spain, the UK and the USA presented their respective national re-certification systems.

\section{Why do we need re-certification?}

In a rapidly evolving field of available therapies and techniques, physicians are continually challenged to deliver a high quality of care. They need to remain current with new developments in medical knowledge, and advances in technology and care coordination. Additionally, highly publicised failures of medical performance, increasing demands for physician accountability and concerns about patient safety have resulted in a search for robust processes to facilitate physicians' lifelong professional competence and performance, and to assess physicians' competence towards the public.

Specialists with many years of experience use pattern recognition for clinical reasoning. In turn, they might be more prone to lose sight of new developments that need to be incorporated into their clinical practice [1]. The challenge of staying up to date with new developments in the medical field remains a burden for all physicians. Surely, a wide range of experience in clinical reasoning characterises a good doctor and increases diagnostic accuracy [2]. However, the literature describes an inverse relationship between age and competence, suggesting that clinical skills decline over time, with individual exceptions [1-4]. This reflects the need for specialists to engage in continuous lifelong learning and development, to maintain and prove their competence. Preferably, physicians should engage in a self-directed and systematic process of lifelong learning. To this end, re-certification
Cite as: Sehlbach C,

Thomson C, Bennett J, et al. Re-certification of respiratory professionals: current practice and the future - educational forum report. Breathe 2017; 13: 77-80. 
systems have been implemented worldwide and serve as a guide for learning activities.

\section{What is re-certification?}

Re-certification entails the maintenance of appropriate and relevant knowledge and skills, which can be periodically demonstrated [5]. Participating in continuous medical education (CME) activities (such as lectures) and engaging in continuous professional development (CPD) activities can act as a means to meet re-certification requirements. In addition to CME, CPD additionally involves strengthening of skills, attitudes and personal growth [6].

Requirements for re-certification can further include (national) examinations, peer and patient review, portfolios, practice visits, and documented clinical practice or patient contacts [7]. Re-certification can involve feedback from different stakeholders and clinical audits to evaluate clinical performance. In particular, multisource feedback can help to identify areas for improvement in knowledge and skills. Multisource feedback often concentrates on more subtle but crucial skills such as communication skills, teamwork and leadership.

In turn, it has been shown that participation in passive, single CPD activities with the main purpose of only collecting credits is less effective in changing physicians' behaviour rather than actively engaging in multiple assessments and feedback exercises. This could be due to the low validity of self-assessed learning needs and identified gaps.

\section{Competence framework}

Whatever service we, as customers, use, we hope to receive the most appropriate one. In medicine, the quality of service provided heavily relies on the healthcare professional's decisions. Quality of care is influenced by other factors, such as the availability of drugs, devices, current evidence, guidelines, multidisciplinary teamwork, etc., yet the competence of medical experts is a critical factor in patient care.

Therefore, competency-based medical education specifically focuses on the domains required from the medical professional (i.e. communication, medical expertise and professionalism). Physicians integrate different roles in their scope of practice: medical expert, communicator, collaborator, leader, health advocate, scholar and professional [8]. These roles, as defined in CanMEDS, or by alternative competence frameworks, can be used to define a competent physician (figure 1).

A re-certification system should ideally involve the assessment of different aspects of professional competence. The assessment of competence can be subdivided into knowledge-based (level 1 and 2) and skills-based assessments (level 3 and 4) with

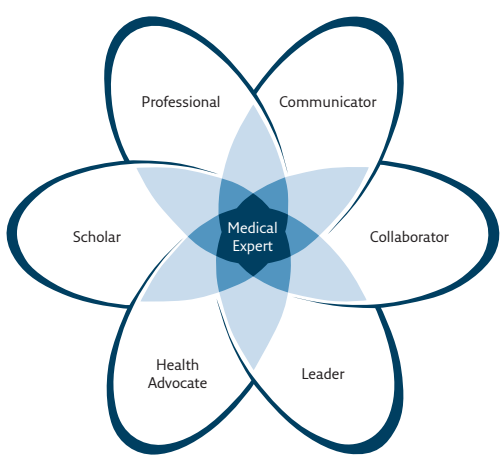

Figure 1 The CanMEDS framework. Copyright (C2015 The Royal College of Physicians and Surgeons of Canada. Reproduced with permission.

specific assessment methods for each level (figure 2) [10]. Knowledge-based assessment can best be complemented by skills-based assessment to cover a breadth of competency $[10,11]$. These can include multiple-choice questions, simulation, direct observations and audits or feedback. To enable a valid assessment of knowledge and performance, a wide breadth of re-certification requirements is recommended, with involvement of different stakeholders and assessment instruments. All activities serving re-certification should be integrated into clinical practice, such as programmes that aim to improve teaching skills, which should be applied in daily routines leading to improved quality of care [12].

\section{International differences in re-certification}

Each system for re-certification needs to be customised to the local situation. National (re-) certification systems differ widely across the world. Not every country has a licensing examination for initial certification in place, for instance. Re-certification processes are common and robust in some countries, whereas in others no re-certification is in place.

Each nation applies its own system defined by context-specific factors such as national legacies, historical and cultural background, epidemiology, demographics, and infrastructure. Elements such as

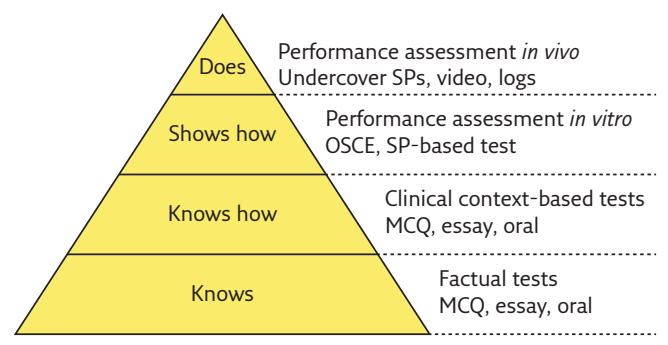

Figure 2 Miller's pyramid of competence [9]. SP: simulated patients; OSCE: objective structured clinical examination; MCQ: multiple-choice questions. Reproduced and modified from [10] with permission from the publisher. 
the healthcare system, medical training and quality standards equally shape the national re-certification system in these countries [13]. The systems vary in complexity, structure, regulations and terminology.

Currently, Spain does not have a certification examination or a re-certification system in place. A legal framework for medical professional development is applied that regulates professional development. The Spanish Respiratory Society acted on it and now offers a professional development document based on the Harmonised Education in Respiratory Medicine for European Specialists (HERMES) syllabus, which aims to reconstruct a programme towards a board examination.

"The ultimate purpose is to carry out an exam equivalent to the HERMES exam. However, this qualification won't be considered official (at least for the time being), since the Spanish Government does not confer it any official recognition," says Spanish panellist Luis Pérez de Llano.

In turn, the UK and the Netherlands have re-certification systems in place in which performance is assessed from different perspectives. In the UK, it is believed that the practice of medicine encompasses not only a high level of knowledge and skill but also important interactions with peers and patients. This is why the British Medical Council suggests four relevant domains to assess clinical practice. These include: 1) knowledge, skills and performance; 2) safety and quality; 3 ) communication, partnership and teamwork; and 4) maintaining trust.

According to Jonathan Bennett, the panellist from the UK, an advantage of the British system is that through the delivery of supporting evidence at an annual appraisal review, physicians must demonstrate compliance with all the domains of Good Medical Practice to progress. At least once every 5 years, every physician must undertake a formal " $360^{\circ}$ " feedback process comprising patients, and medical and nonmedical colleagues. The reflective component of practice is also a strength and works toward coverage of all aspects of work practice. However, Bennett also mentions downsides of the UK programme, such as the costs of organisation and a potential for nepotism, as colleagues and friends can potentially act as appraisers.

"However, I have come to accept that it is probably a better system than an exam based re-certification process which essentially only assesses knowledge and skills," he said.

The Dutch re-certification system focusses on lifelong learning and maintaining competences. From 2017 onwards, it will entail evaluation of the individual and group functioning, as well as peers' and patients' feedback. Collation of work will also become a re-certification requirement. A potential pitfall of collecting CPD credits is that the tendency is for specialists to seek learning activities within their own field of expertise rather than from areas where growth is needed. Another disadvantage, which Frank Smeenk from the Netherlands points out, is the risk of bureaucracy. He also describes the challenge of using the current system as a lifelong learning system with a PDCA (plan, do, check and act) cycle. Learning and development objectives for the subsequent cycle should arise from the individual and group evaluation. Likewise, performance improvement in targeted areas of individual learning objectives can be evaluated.

In the USA there is a national re-certification system for each medical specialty administered by the American Board of Internal Medicine (ABIM). This process has been evolving over the past few years. Currently, a re-certification examination is required every 10 years for diplomates who received their certification after 1990. In recent years, self-assessment maintenance of certification (MOC) modules in medical knowledge and performance improvement increased from 100 points every 10 years to 100 points every 5 years, with a continuous requirement and with additional requirements in patient voice and patient safety. Following feedback from specialty societies, diplomates and an ABIM task force, the requirement for a 10-year secure examination is being re-evaluated with potential changes to smaller assessment units in a rolling fashion. Additionally, the MOC requirements and certifying organisations have been reframed under the direction of the Accreditation Council for Continuing Medical Education, and requirements for patient safety, patient voice and performance improvement are undergoing reconsideration. Panellist Carey Thomson points out that "while a strength of this system may be a uniformed, easy to manage process through content based quizzes and points tallied, challenges occur with assessing varied practice patterns and areas of expertise through a standardized examination, and the lack of a system for assessment of competence". Examinations and MOC activity are not linked to quality metrics or patient outcomes. An evaluation of competence and professionalism are left to individual hospitals, clinics, state licensing boards, and division/departmental leaders at the local level. Another downside, according to Thomson, is the cost to practicing physicians, which come in the form of thousands of dollars every 5 years and at each re-certification cycle. This cost is an additional layer of expense for physicians who are also paying for multiple other licensing requirements at the state and federal level. There is a strong incentive to recertify in the USA as many hospitals require certification for practice.

The re-certification system for respiratory specialists in Japan is driven by the Japanese Respiratory Society, so that, according to Akihito Yokoyama, the credibility of the current system might be low for some people. Another drawback of the Japanese system, which Akihito Yokoyama mentioned, is the lack of incentives for specialists to re-certify. Regarding the actual evaluation 
of competence, he described the absence of assessment of professionalism or patient outcomes. Nevertheless, he described that the system seems to contribute to good and standardised practice. Japan has a 5-year cycle for re-certification in place in which credits need to be collected. Credits can be obtained by attending the national society meeting. This might however change in the future as the Japanese medical specialty board has challenged itself to uniform the certification and re-certification of all individual specialty societies. By doing so it aims to increase the reliability of specialist's medical care within the next years.

\section{Discussion}

The presentation of national re-certification approaches during the educational forum was followed by a panel discussion on the effectiveness and internationalisation of re-certification, chaired by Ildikó Horváth from Hungary. Any formalised recertification system that is able to improve the level of competence substantially depends on different national healthcare systems and cultures. A widespread international effort might be able to scale this movement up and strengthen re-certification processes to further improve healthcare quality.
"Building on the commitment of the ERS towards education, and taking the wide experience and knowledge of its members into account, I can foresee that the Society could play an innovative and creative role in providing training material through different channels. The ERS can contribute to the richness of postgraduate education and could facilitate the harmonization of different recertification systems all around the globe," says Ildikó Horváth.

We will probably see increasing implementation of re-certification systems across the world. The future will show where and how re-certification will be implemented, and which methods will be used to evaluate competence. The actual effect of re-certification on quality of care needs to be investigated further, as a direct link is difficult to establish [14, 15].

The ERS can play a leading role in this process as one of the first medical societies researching possibilities for re-certification in an effort to understand future possibilities. A concrete first step could be the provision of the core topics and disease areas as well as forms of teaching, learning and assessments within a comprehensive CME/CPD framework for respiratory specialists.

\section{Conflict of interest}

Disclosures can be found alongside this article at breathe.ersjournals.com

\section{References}

1. Holmboe ES, Lipner R, Greiner A. Assessing quality of care knowledge matters. JAMA 2008; 299: 338-340.

2. Eva KW. The aging physician: changes in cognitive processing and their impact on medical practice. Acad Med 2002; 77: Suppl. 1, S1-S6.

3. Hawkins RE, Lipner RS, Ham HP, et al. American Board of Medical Specialties Maintenance of Certification: theory and evidence regarding the current framework.J Contin Educ Health Prof 2013; 33: Suppl. 1, S7-S19.

4. Choudhry NK, Fletcher RH, Soumerai SB. The relationship between clinical experience and quality of health care. Ann Intern Med 2005; 142: 260-273.

5. Ahmed K, Khan RS, Darzi A, et al. Recertification: what do specialists think about skill assessment? Surgeon 2013; 11 : 120-124.

6. Busari JO, Duits A. Postgraduate medical education. In: Walsh $\mathrm{K}$, ed. Oxford Textbook of Medical Education. Oxford, Oxford University Press, 2013; pp. 340-349.

7. Merkur S, Mossialos E, Long M, et al. Physician revalidation in Europe. Clin Med (Lond) 2008; 8: 371-376.

8. Frank JR, Snell LS, Sherbino J. CanMEDS 2015 Physician Competency Framework. Ottawa, Royal College of Physicians and Surgeons of Canada, 2015
9. Wass V, et al. Assessment of clinical competence. Lancet 2001; 357: 945-949.

10. Miller GE. The assessment of clinical skills/ competence/performance. Acad Med 1990; 65: S63-S67.

11. Amin Z, Chong YS, Khoo HE. Practical Guide To Medical Student Assessment. Singapore, World Scientific, 2006.

12. Davis D, Evans M, Jadad A, et al. The case for knowledge translation: shortening the journey from evidence to effect. BMJ 2003; 327: 33-35.

13. Brennan J, Shah T. Quality assessment and institutional change: experiences from 14 countries. High Educ 2000; 40: 331-349.

14. Hayes J, et al. Association between physician timeunlimited vs time-limited internal medicine board certification and ambulatory patient care quality. JAMA 2014; 312: 2358-2363.

15. Boulet J, van Zanten M. Ensuring high-quality patient care: the role of accreditation, licensure, specialty certification and revalidation in medicine. Med Educ 2014; 48: 75-86. 